DOI 10.37882/2500-3682.2021.05.17

\title{
АНТРОПОЛОГИЧЕСКИЕ ОСНОВАНИЯ КОНЦЕПЦИИ УСТОЙЧИВОГО РАЗВИТИЯ
}

\section{ANTHROPOLOGICAL FEATURES OF THE DISCOURSE OF SUSTAINABLE DEVELOPMENT}

\section{S. Kliminskaya}

Summary: The article is devoted to the analysis of the concept of sustainable development and its anthropological characteristics. The author analyzes the changes in social life caused by various factors that can be leveled with the implementation of the sustainable development strategy. The article emphasizes the relevance of the anthropocentric approach in creating a new type of society based on the humanities. The formation of a new knowledge-based system of the concept of sustainable development, occurs during communication activities between representatives of the new society.

Keywords: anthropology, sustainable development, knowledge-based society, knowledge system, concept.

\section{Введение}

K онцепция устойчивого развития является результатом эволюционного развития учения В.И. Вернадского о биосфере, подчеркивающей взаимосвязь природы и человека [1]. Теория ученого о рациональном использовании природных ресурсов и ответственность человека, как разумного элемента биосферы, за сохранение планеты подразумевает формирование ноосферного мировоззрения. Новая система взглядов предполагает развитие потенциала человека, который эффективно использует имеющиеся природные ресурсы и достижения научно-технического прогресса для создания более совершенного гражданского общества.

Подобный подход требует формирования долгосрочной социально-экономической стратегии, направленной на достижение поставленных перед обществом целей, которые были сформулированы и зафиксированы в положениях Конференции ООН 1992 г. [19], таких как: определение дела сохранения окружающей среды и мира на планете приоритетной социально-этической задачей для каждого члена общества, организации и учреждения; оптимизация рационального использования имеющихся ресурсов; формирование плодотворного международного взаимодействия для достижения поставленных целей; регулирование демографической ситуации и планирование градостроительной деятельности; развитие науки и образования, а также контроль

\author{
Климинская Светлана Леонидовна \\ к.филол.н., дочент, МГИМО МИД РФ \\ kvi62@inbox.ru
}

Аннотация: Статья посвящена анализу концепции устойчивого развития и ее антропологических характеристик. Автор анализирует изменения в жизни общества, вызванные различными факторами, негативное воздействие которых может быть минимизировано посредством реализации стратегии устойчивого развития. В статье подчеркивается актуальность антропоцентрического подхода при создании общества нового типа, основой которого является гуманитарное знание. Формирование новой системы знаний концепции устойчивого развития происходит при развёртывании дискурса устойчивого развития.

Ключевые слова: антропология, устойчивое развитие, общество знаний, система знаний, концепт.

за распространением информации и знаний для всестороннего развития человека и др. Данная декларация охватывает все сферы общественной жизни и направлена на устранение негативных последствий стремительного развития человечества.

Таким образом концепция устойчивого развития стала цивилизационной моделью, основу которой составляет баланс между удовлетворением социальноэкономических потребностей общества и сохранением окружающей среды. Однако преобразования во всех сферах общественной жизни, а также критические экономические и социальные противоречия 20 века привели к цивилизационному кризису [2], что выразилось в нехватке территорий и природных ресурсов и борьбе за них на макро- и микроуровнях.

\section{Антропологические характеристики коншепчии устойчивого развития}

Глобализационные изменения, а также развитие технологий и изменения в интеллектуальной сфере $[11,12]$ свидетельствуют о становлении в настоящее время информационно-экологического общества, способного использовать экономические, социальные и политические рычаги, а также интеллектуальные и технологические достижения для развития самого человека и разумного использования природных ресурсов для сохранения условий, пригодных для дальнейшего существования бу- 
дущих поколений. Кроме того, интеграционные процессы вызвали изменения антропологического характера, которые можно классифицировать следующим образом $[4,5,7,13,15,16,17,20]$ :

- политические - явления, вызванные демократическими преобразованиями и представляющие собой ценность в современном обществе (широта взглядов, политические свободы и др.)

- социальные - духовные и этические принципы, направленные формирование общественного сознания, при этом (статус человека в обществе; активность жизненной позиции; участие в общественной жизни, возможность действовать в соответствии с личными интересами, принимать решения, опираясь на личный опыт и др.),

- экономические - статус человека как элемента экономических взаимоотношений (характер производства; характер потребления; создание хозяйственной этики; отношение к труду; отношение к собственности и др.)

- когнитивные - трансформации, описывающие изменения в действительности и способы их отражения в сознании человека (информационное равенство; манипуляция сознанием; глобализация сознания и др.)

- гуманитарные - как часть социального процесса, гуманитарные явления обеспечивают человеческие свободы одновременно ограничивая их при необходимости во избежание процессов самоуничтожения общества (запрет на деструктивное проявление человеческой сущности, распространение гуманитарного знания, стабилизация численности населения, справедливый доступ и распределение ресурсов, мобилизация творческих сил и идеалов в целях сохранения мира и глобального партнерства и др.).

Изменение антропологических характеристик свидетельствует о применении антропоцентрического подхода к формированию современного общества, что зафиксировано в концепции устойчивого развития и предполагает применение гуманитарных критериев к оценке деятельности человека и распространение гуманитарного знания для урегулирования насущных проблем [6].

\section{Гуманитарное знание как основа коншепчии УР}

Гуманитарное знание, составляет основу общества, общественного и межличностного диалогов, а также межгосударственного взаимодействия, так как представляет собой особую ценность и передается от поколения к поколению. Значимость гуманитарного знания заключается в том, что развивает в человеке объективность и формирует его мировоззрение, поскольку связано с природой, гуманизмом, развитием личности. Гуманитарное знание опирается на культурное наследие народа (мифы, религиозные святыни, литературные произведения и т.п), что дает возможность представителю общества постигать действительность путем декодирования семиотических знаков, транслируемых в национальном культурном наследии [10].

Гуманитарное познание направлено на приведение в соответствие действительности и сознания индивида [18]. Однако современное общество является сложным многополярным феноменом, поэтому гуманитарное познание не ограничивается знаниями о человеке, культуре и истории, оно интегрирует разнообразный научный и практический опыт, образуя ценностно-мировоззренческую систему. Сегодня научному и практическому познанию свойственна междисциплинарность, что особенно актуально для концепции устойчивого развития.

Гуманитарное познание имеет рефлексивный характер, т.е. рождается при переосмыслении информации, полученной из различных источников, в том числе в процессе общения при артикуляции персонального видения проблемы, ценностей и приоритетов [14]. Дискуссия по проблемам устойчивого развития предполагает столкновение позиций и обмен мнениями и знаниями по актуальным общественным вопросам. При этом происходит фокусирование коммуникации на отдельном аспекте/предмете обсуждения, т.е. на первое место выходит интерпретация интерсубъективных смыслов, представляющих интерес для коммуникантов, в результате чего генерируется новое знание, которое впоследствии инкорпорируется в систему знаний и в современное мировоззрение.

В рамках концепции устойчивого развития в фокус внимания попадают вопросы экологического, экономического, социального и технологического характера. Перечисленные сферы деятельности являются жизненно важными для современного общества и образовывают систему отраслевых знаний, необходимых для реализации стратегии УР. Отраслевые знания представляют сбой совокупность научных фактов, накопленного и нового профессионального опыта, экспертных оценок, циркулирующих в отраслевом дискурсе [8]. С развитием технологий и усилением влияния СМИ на общественную жизнь, общественный диалог по проблемам УР осуществляется в различных формах (научное обсуждение, общественные дискуссии, выступления специалистов в СМИ, размещение информации в интернет-пространстве и т.п), при этом наблюдается пересечение и взаимодействие отраслевых дискурсов.

Система знаний концепции устойчивого развития является упорядоченным абстрактным представлением реальности. Система характеризуется открытостью и аутопоэзностью [21], т.е. она способна принимать новые знания и самостоятельно производить их путем ре- 
пликации своих элементов, образующиеся в процессе коммуникации по данным вопросам. Система знаний концепции устойчивого развития опирается на знания из таких научных областей, как экономика, экология, социология, технологии, политика, которые представляют собой совокупности институциональных системно организованных понятий, необходимых для принятия решений по обсуждаемым проблемам.

Элементы данных институциональных знаний представлены концептами, содержательной стороной которых является фундаментальное знание. В речи концепты реализуются семантическими единицами, принадлежащими институциональным семантическим полям, которые образуют пропозициональную основу концепции устойчивого развития.

В силу того, что в настоящее время мы наблюдаем формирование общества знаний (knowledge based society) [3], в котором ценится умение анализировать, формировать и обмениваться информацией, генерировать новые знания в дискуссионном процессе, реализуя собственный познавательный потенциал, становится естественным для современного человека. В этих условиях индивид удовлетворяет потребность в получении информации, как человек нового типа - Homo Informaticus [5], а также реализовывать коммуникативные и социальные функции, принимая участие в решении социально важных проблем.

Развитие технологий и их широкое внедрение в жизнь общества облегчают поиск информации и организацию общественного взаимодействия между представителями различных общественных организаций, членов научных сообществ и других лиц, вне зависимости от культурной принадлежности, уровня и специфики образования, что обусловливает развертывание полилогической дискуссии и формирование дискурса устойчивого развития. На фоне конвергенции институциональных субдискурсов [9] происходит контактирование знаниевых структур в ходе когнитивно-коммуникативного взаимодействие, результатом которого является формирование нового знания в форме гибридных концептов устойчивого развития. Примером гибридных концептов могут служить такие понятия, как green marketing, green consumerism, carbon tax, eco-labelling, sustainable investment как результат взаимодействия экономической и экологической систем знания; slow city, slow food, green agenda, green transport, sustainable Christmas tree (наложение социаль- ного и экологического субдискурсов) и др.

Данные концепты представляют собой семантикокогнитивные бленды, ценность которых заключается в новизне и актуальности представляемых ими понятий, необходимых для решения поставленных задач в рамках концепции устойчивого развития. Данное свойство делает новое знание общественно значимым, что ведет к его инкорпорированию в общественную систему ценностей и закреплению соответствующего гибридного концепта в языковой системе.

Система знаний устойчивого развития является открытой, ее наполнение происходит при возникновении изменений в общественной жизни, с появлением новых вызовов и угроз. Образующиеся концепты могут мигрировать из одной структуры знаний в другую, отражая трансформации в жизни общества, что в свою очередь отражается на антропологических характеристиках общества, таких как политические, социальные, экономические, когнитивные и гуманитарные. Таким образом, наблюдается взаимосвязь между когнитивно-коммуникативной деятельностью человека, гуманитарным знанием, как основой современного общества, и его антропологическими параметрами.

\section{Зак^ючение}

Преобразования общественной жизни, вызванные бурным экономическим развитием, политическими кризисами, развитием науки и техники, подтвердили актуальность идей В.И. Вернадского о создании общества нового типа, где будет соблюдаться баланс между потребностями общества и сохранением планеты для будущих поколений. Концепция устойчивого развития, разработанная с учетом социальных потребностей и угроз, стала мировоззрением и стратегией развития для человечества. Реализация данной стратегии вызвала изменение антропологических характеристик и выявило актуальность антропологического подхода при создании общества нового типа. Основу нового общественного порядка составляет гуманитарное знание, которое включает опыт предыдущих поколений и новое знание, формирующееся при развертывании дискурса устойчивого развития в форме гибридных концептов и направленное на реализацию концепции устойчивого развития. Система знаний концепции устойчивого развития является открытой эутопоэтической системой.

\section{ЛИТЕРАТУРА}

1. Вернадский В.И. 0 науке: в 2 т. Дубна: «Феникс», 1997. Т. 1. Научное знание. Научное творчество. Научная мысль. Т.1. Научная мысль как планетное явление. С. 303-538. 
2. Гнатюк В.С. Устойчивое развитие социума в ситуации постсовременности // Вестник ВолГУ. Сер.: Филосо.фия. Социология и социальные технологии. 2010. № 7-12. C.69-76.

3. Иноземцев В.А., Иноземцева Ю.В. Проблема информационных ресурсов в условиях формирования ноосферной экологической цивилизации устойчивого типа // Известия МГТУ. 2013. №4. URL: http://cyberleninka.ru/article/n/problema-informatsionnyh-resursov-v-usloviyah-formirovaniya-noosfernoyekologicheskoy-tsivilizatsii-ustoychivogo-tipa (Дата обращения: 20.02.2021).

4. Коваженков М.А. Управленческая социализация как специфическая антропологическая характеристика // Известия ВолгГТУ. 2008. №5. С.7-9.

5. Колин К.К. Человек в информационном обществе // Вестник Кемеровского государственного университета культуры и искусств. 2007. №2. С.22-31.

6. Корниенко В.И. Гуманитарный прогресс человеческого общества // Вестник ЧелГУ. 2007. №17. URL: https://cyberleninka.ru/article/n/gumanitarnyyprogress-chelovecheskogo-obschestva (Дата обращения: 15.01.2021).

7. Корякин В.В., Орлов В.В. Труд, стоимость, собственность В современном обществе (философский анализ) // Вестник ВятГУ. 2010. №4. С.46-54.

8. Куликова 0.В. Типы знаний и их взаимодействие в экономическом дискурсе // Вестник Московского государственного лингвистического университета. 2013. Вып. 25 (685). С. 34-40.

9. Куликова 0.В., Климинская С.Л. Концептуальное взаимодействие в динамике дискурса устойчивого развития (на материале английского языка) // Современная наука: актуальные проблемы теории и практики. Гуманитарные науки. 2018. №3. URL: http://www.nauteh-journal.ru/index.php/ru/--gn1803/4394-а (Дата обращения: 20.01.2021).

10. Малинкин А.Н. Гуманитарное знание в борьбе эпистемологических парадигм (к истории вопроса) // Гуманитарное знание и вызовы времени. СПб.: Центр гуманитарных инициатив; Университетская книга, 2014. С. 112-114.

11. Мамедов Н.М. Исторический процесс и концепция устойчивого развития // Век глобализации. 2010. №2. URL: https://cyberleninka.ru/article/n/ istoricheskiy-protsess-i-kontseptsiya-ustoychivogo-razvitiya (Дата обращения: 15.01.2021).

12. Эскиндаров М.А., Грузина Ю.М., Фирсова И.А., Мельничук М.В. Компетенции человеческого капитала в высокотехнологичных и наукоемких отраслях экономики // Экономические и социальные перемены: факты, тенденции, прогно3. 2020. Т. 13. № 6. С. 199-214.

13. Нагаева С.К. Человек в структуре гражданского общества 1политико-антропологический подход) // Научные ведомости Белгородского государственного университета. Сер.: История. Политология. 2011. №13 (108). С.170-175.

14. Пахонина Е.В. Специфика гуманитарного типа научного познания // Актуальные проблемы гуманитарных и естественных наук. 2013. №4. URL: https:// cyberleninka.ru/article/n/spetsifika-gumanitarnogo-tipa-nauchnogo-poznaniya (Дата обращения: 20.02.2020).

15. Прикладовский С.А. Детерминация свободы в условиях современной социальной реальности // Научно-технические ведомости Санкт-Петербургского государственного политехнического университета. Общество. Коммуникация. Образование. 2012. №143. URL: https://cyberleninka.ru/article/n/ determinatsiya-svobody-v-usloviyah-sovremennoy-sotsialnoy-realnosti (дата обращения: 23.02.2021).

16. Уильямс Бернард От «Свободы вообще» к политической свободе // История философии. 2010. №15. URL: https://cyberleninka.ru/article/n/ot-svobodyvoobsche-k-politicheskoy-svobode.

17. Храпов С.А. Антропологический фактор становления потребительской направленности общественного сознания современной России // Вестник ВолГУ. Сер. 7: Философия. Социология и социальные технологии. 2009. №1. С.52-57.

18. Черникова И.В. Эволюционная эпистемология как когнитивная практика постнеклассической науки // Вестн. Том. гос. ун-та. Сер.: Философия. Социология. Политология. 2008. №1 (2). URL: https://cyberleninka.ru/article/n/evolyutsionnaya-epistemologiya-kak-kognitivnaya-praktika-postneklassicheskoy-nauki (Дата обращения: 20.02.2021).

19. Документ 0OH A/CONF.151/26/Rev.1 (Vol. I) URL: http://www.un.org/ru/documents/decl_conv/declarations/riodecl (Дата 0бращения: 15.01.2021). [Dokument OON A/CONF.151/26/Rev.1 (Vol. I). URL: http://www.un.org/ru/documents/decl_conv/declarations/riodecl (accessed: 15.01.2021).]

20. Byron Good, Andrew McDowell Belief, Anthropology of // International Encyclopedia of the Social \& Behavioral Sciences (Second Edition) 2015, Pages 493-497. URL: https://www.sciencedirect.com/science/article/pii/B9780080970868120240

21. Maturana H., Varela F. Autopoiesis: the organization of the living. In: Maturana H., Varela F. Autopoiesis and Cognition. Boston, 1980, P. 63 - 134.

(с) Климинская Светлана Леонидовна (kvi62@inbox.ru).

Журнал «Современная наука: актуальные проблемы теории и практики» 